\title{
Volatile Compounds from Japanese Noodles, "Udon,” and their Formation During Noodle-Making
}

\author{
Narisawa $\mathrm{T}^{1,2 *}$, Nakajima $\mathrm{H}^{1}$, Umino $\mathbf{M}^{1}$, Kojima $\mathrm{T}^{1}$, Asakura $\mathrm{T}^{2}$ and Yamada $\mathbf{M}^{3}$ \\ ${ }^{1}$ Saitama Industrial Technology Center Northern Laboratory, Kumagaya-Shi, Saitama, Japan \\ ${ }^{2}$ Department of Applied Biological Chemistry, Graduate School of Agricultural and Life Sciences, The University of Tokyo, Bunkyo-ku, Tokyo, Japan
}

${ }^{3}$ Department of Applied Chemistry, School of Advanced Engineering, Kogakuin University, Hachioji-Shi, Tokyo, Japan

\begin{abstract}
Flavor is one of the important factors for udon, white salted Japanese noodles that are produced by mixing flour, salt, and water prior to being shaped and boiled. Using dynamic headspace extraction-gas chromatography/mass spectrometry, we analyzed the volatile compounds emitted from the flour, dough, and boiled noodles to clarify the formation mechanism of the udon flavor. The volatile compound profiles were analyzed by principal component analysis; those from the dough and noodles were compared to those from the flour. Hydrocarbons were the main compounds emitted from the flour, and aldehydes and ketones from the dough and noodle. These aldehydes and ketones were presumed to be generated from the enzymatic oxidation of unsaturated fatty acids by lipoxygenase (LOX) upon the addition of water. Notably, the abundances of aldehydes and ketones increased during the noodle-making process, affecting the volatile compound profiles of the noodles. Noodles prepared from Nourin 61 flour, which are preferred by consumers, had higher contents of aldehydes and ketones and higher LOX activity. Therefore, the unique volatile compound profiles of udon may be generated by the LOX activity in wheat flour, and these aldehydes and ketones may contribute to the characteristic udon flavor.
\end{abstract}

Keywords: Wheat flour; Noodle-making process; Volatile compound profile; GC/MS; Lipoxygenase

\section{Introduction}

Flavor is one of the important factors for food, and there is growing interest in studying the flavor characteristics of cereal products $[1,2]$. Some researchers suggest that the volatile compounds in cereal flour may affect the flavor of processed foods such as bread [3]; sourdough [4]; and extrusion cooking products of oats [5,6] and wheat flour [7]. Noodles are a well-known, standard wheat product. In Asian countries, noodles made from wheat are favored over the white salted noodle "udon" or the yellow alkaline noodle "Chinese noodle". In Western countries, these types of noodles are as popular as pasta. Pasta is one of the most studied cereal products. The volatile compound profiles of durum wheat (Triticum durum) and cooked pasta have been investigated [8-10]. Beleggia et al. [8] reported that the flavor of pasta depends on the durum wheat cultivar. Changes in volatile compounds during the cooking process were analyzed using solid-phase micro extraction followed by gas chromatography/mass spectrometry (GC/MS). In cooked pasta, alcohols (i.e., 1-pentanol, 1-hexanol, and 1-octanol) and aldehydes (i.e., hexanal and benzaldehyde) were significantly linked to the presence of unsaturated fatty acids, such as linoleic and alphalinolenic acid. Therefore, these volatile compounds in cooked pasta have been associated with the oxidation of unsaturated fatty acids.

However, there have been few studies on the volatile compounds and their formation in Asian noodles [11,12] compared with those in pasta [8-10]. Suzuki et al. [11] showed a correlation between enzyme activities and volatile compounds in boiled buckwheat noodles. These studies compared the volatile compounds in the raw materials with those in their end-products. Udon is a traditional Japanese food; its shape resembles that of spaghetti. However, the udon-making process is simpler than the spaghetti-making process. Udon is made from common wheat (T. aestivum) flour and water containing $\mathrm{NaCl}$. Subsequently, the noodle is shaped and cooked. The udon-making process does not require fermentation or any additives except $\mathrm{NaCl}$. Therefore, the flavor of udon is strongly affected by the wheat flour itself and depends on the noodle-making process. Australian standard white (ASW) flour is often used as the raw material for udon because it imparts superior color, color stability, and texture characteristics to the noodles. Japanese wheat cultivars, such as "Norin 61" (N61), one of the most popular wheat cultivars for udon, possess unique taste and flavor and are favored over ASW flour [13]. However, the use of new wheat cultivars, such as "Satonosora" (Sato), has resulted in noodles that are less flavorful than N61-based noodles and increased the demand for flavorful wheat flour. Recently, Starr et al. [14] analyzed the volatile compound differences of flour from 81 varieties and landraces of common wheat using dynamic headspace extraction (DHE) followed by GC/MS; 72 volatile compounds were identified. They reported that the modern bred varieties were characterized by higher levels of terpenes, pyrazines, and straight-chain aldehydes and lower levels of esters. Starr et al. [15] noted that variations in the wheat flavor directly affected the flavor of the end-product, such as bread. However, the mechanism of volatile compound formation during the udon-making process and the key compounds behind the udon-specific flavor remain to be determined.

This study investigated the changes in the volatile compound profiles during the udon-making process and clarified the mechanism of volatile compound formation. We analyzed the volatile compounds in flour, dough, and noodles using DHE-GC/MS and compared the changes in the volatile compound profiles by principal component analysis (PCA). Some volatile compounds, such as hexanal, (E)-2-

*Corresponding author: Tomoyuki Narisawa, Saitama Industrial Technology Center Northern Laboratory, Kumagaya-Shi, Saitama, Japan, Tel: +81-48-5210614, Fax: +81-48-525-6052; E-mail: narisawa-t@saitama-itcn.jp

Received October 11, 2017; Accepted November 02, 2017; Published November 09, 2017

Citation: Narisawa T, Nakajima H, Umino M, Kojima T, Asakura T, et al. (2017) Volatile Compounds from Japanese Noodles, "Udon," and their Formation During Noodle-Making. J Food Process Technol 8: 700. doi: 10.4172/2157-7110.1000700

Copyright: (c) 2017 Narisawa T, et al. This is an open-access article distributed under the terms of the Creative Commons Attribution License, which permits unrestricted use, distribution, and reproduction in any medium, provided the original author and source are credited. 
hexenal and 1-hexanol observed in pasta [8] and wheat flour [14], are derived from the oxidation of unsaturated fatty acids by lipoxygenase (LOX) [16-18]. Therefore, we analyzed the fatty acid composition and LOX activities to clarify the formation mechanisms of the volatile compounds in the noodle-making process.

\section{Materials and Methods}

\section{Wheat flour}

First-grade and $2^{\text {nd }}$ grade N61 samples, a $1^{\text {st }}$ grade Ayahikari (Aya) sample, and $1^{\text {st }}$ grade and $2^{\text {nd }}$ grade Sato samples were prepared as commercial products (Maeda Shokuhin Inc., Saitama, Japan). Firstgrade and $2^{\text {nd }}$ grade ASW samples were prepared by Nisshin Flour Milling Inc., Tokyo, Japan. As this study dealt with enzymatic activity and the enzymes are generally present near bran, two grades of wheat flours with different contamination ratios of bran were used as experimental samples.

The moisture content of the flour samples was determined using the modified AACC Approved Method 44-19 [19] by measuring the weight lost after drying the samples in an air oven at $135^{\circ} \mathrm{C}$ for $1 \mathrm{~h}$. The ash and protein contents were determined by AACC Approved Methods 08-01 and 46-11A [19]. The lipid content was determined using the modified AACC Approved Method 30-10 [19] by weighing the samples after removing the solvent using an evaporator and a stream of dry nitrogen gas. The lipids extracted from wheat flour were applied to the following fatty acid composition analysis.

\section{Fatty acid composition analysis}

According to the official standard method 2.4.1.2-1996 (Boron Trifluoride-Methanol Method) of the Japan Oil Chemists' Society [20], fatty acid methyl ester (FAME) derivatives were prepared from the extracted lipid. In brief, $50 \mathrm{mg}$ of extracted lipid was treated with $1 \mathrm{ml}$ of a $0.5 \mathrm{M} \mathrm{NaOH}$ methanol solution for $10 \mathrm{~min}$ at $80^{\circ} \mathrm{C}$ in a $50 \mathrm{ml}$ conical flask connected to a Liebig condenser, followed by the addition of $1 \mathrm{ml}$ of a methanol solution of $\mathrm{BF}_{3}$-methanol complex (Wako Pure Chemical Industries, Ltd., Osaka, Japan). After heating for $2 \mathrm{~min}$ at $80^{\circ} \mathrm{C}, 5 \mathrm{ml}$ of $n$-hexane was added, and the sample was heated for $1 \mathrm{~min}$ at $80^{\circ} \mathrm{C}$. After cooling, saturated $\mathrm{NaCl}$ solution was added to the reaction flask. The n-hexane phase, containing the FAMEs, was transferred into a test tube, to which anhydrous $\mathrm{Na}_{2} \mathrm{SO}_{4}$ was added to remove water. The resultant solution was subjected to GC/MS analysis. The FAMEs from each sample were analyzed using GC/MS (GC: Agilent Technologies 6890N, Agilent Technologies, US; MS: JEOL Automass Sun, JEOL Ltd., Tokyo, Japan) with a DB-WAX column (Agilent Technologies; length, $30 \mathrm{~m}$; inner diameter, $0.25 \mathrm{~mm}$; film thickness, $0.25 \mu \mathrm{m})$. Helium with 99.9999\% purity was employed as the carrier gas at a constant flow rate of $1.5 \mathrm{ml} / \mathrm{min}$. The injector temperature was $250^{\circ} \mathrm{C}$, and the split ratio was $1 / 50$. The $n$-hexane phase including the FAMEs was injected via a 7683 series injector (Agilent Technologies), and the injection volume was $1 \mu \mathrm{l}$. The oven temperature was held at $50^{\circ} \mathrm{C}$ for $1 \mathrm{~min}$, increased to $200^{\circ} \mathrm{C}$ at a heating rate of $25^{\circ} \mathrm{C} / \mathrm{min}$ and to $230^{\circ} \mathrm{C}$ at a heating rate of $3^{\circ} \mathrm{C} / \mathrm{min}$, and then held at $230^{\circ} \mathrm{C}$ for $18 \mathrm{~min}$. The interface temperature was $200^{\circ} \mathrm{C}$. The mass spectrometer was operated in electron ionization mode at $70 \mathrm{eV}$, and its ionization source was maintained at $200^{\circ} \mathrm{C}$. The FAMEs were detected in selected ion monitoring mode using the four fragment ions $\mathrm{m} / \mathrm{z} 74, \mathrm{~m} / \mathrm{z} 79, \mathrm{~m} / \mathrm{z} 81$ and $\mathrm{m} / \mathrm{z} 87$ as described by Thurnhofer et al. [21].

\section{Preparation of dough samples for GC/MS analysis}

In a beaker, $7 \mathrm{~g}$ of wheat flour was mixed with $3.5 \mathrm{ml}$ of water containing $0.14 \mathrm{~g}$ of $\mathrm{NaCl}$ to obtain homogeneous dough samples. All GC/MS measurements were performed within $2 \mathrm{~h}$ after the dough preparation.

\section{Preparation of noodles}

Two hundred grams of wheat flour were mixed with $74 \mathrm{ml}$ of water containing $4.0 \mathrm{~g}$ of $\mathrm{NaCl}$ in a vertical mixer (Kanto Kongoki Industrial Co., Tokyo, Japan) for $30 \mathrm{~s}$ at $105 \mathrm{rpm}$, for $30 \mathrm{~s}$ at $170 \mathrm{rpm}$, and for 3 min at $260 \mathrm{rpm}$. The mixed material was sheeted through the rolls of an Ohtake noodle machine (Ohtake Noodle Machine Mfg. Co., Tokyo, Japan) with a $4 \mathrm{~mm}$ gap between the rolls. The dough sheet was then folded and fed through the sheeting rolls again to combine the two layers, and this process was repeated two more times. The combined sheet was allowed to rest for $1 \mathrm{~h}$ at room temperature and then rolled twice while reducing the gap in a stepwise manner to $3.0 \mathrm{~mm}$ and 2.5 $\mathrm{mm}$, sequentially. The dough sheet was cut by the cutting rolls into raw noodles that were $3.0-\mathrm{mm}$ wide and $20-\mathrm{cm}$ long. Forty grams of the raw noodles were cooked in $400 \mathrm{ml}$ of boiling water for $8 \mathrm{~min}$.

The moisture content of the noodles was measured using the AACC Approved Method 44-19 [19] by measuring the weight lost after drying the noodle samples at $135^{\circ} \mathrm{C}$ for $2 \mathrm{~h}$.

\section{Volatile compound analysis}

The volatile compounds in each sample were analyzed using GC/ MS (GC: Agilent Technologies 7890A; MS: JEOL JMS-Q1000GC MkII) with a DB-WAX column (Agilent Technologies; length, $60 \mathrm{~m}$; inner diameter, $0.25 \mathrm{~mm}$; and film thickness, $0.25 \mu \mathrm{m}$ ). Helium with $99.9995 \%$ purity was employed as the carrier gas at a flow rate of $1 \mathrm{ml} /$ $\mathrm{min}$. The interface temperature was $200^{\circ} \mathrm{C}$. The mass spectrometer was operated in electron ionization mode at $70 \mathrm{eV}$, and its ionization source was maintained at $200^{\circ} \mathrm{C}$. The mass spectra were collected from $\mathrm{m} / \mathrm{z} 29$ to 300 , generating 2 scans/s.

The wheat flour ( $3.3 \mathrm{~g})$ and boiled noodles $(5.0 \mathrm{~g})$ were placed in $20 \mathrm{ml}$ glass vials. The noodle dough $(5.0 \mathrm{~g})$ was shaped into flakes in a beaker before being placed in the vials. The vapor in the vial headspace, which was thermally equilibrated at $80^{\circ} \mathrm{C}$ for $20 \mathrm{~min}$, was adsorbed onto a solid phase (GL trap1; GL Sciences Inc., Tokyo, Japan) by pressurizing the vial to $140 \mathrm{kPa}$ in an autosampler (S-trap; JEOL). After adsorption, the solid phase was dried by flowing helium for $1.5 \mathrm{~min}$ and then heated at $200^{\circ} \mathrm{C}$ for 3 min to desorb and inject the compounds into the GC column. The GC oven temperature was held at $40^{\circ} \mathrm{C}$ for 10 min, increased to $220^{\circ} \mathrm{C}$ at a heating rate of $6^{\circ} \mathrm{C} / \mathrm{min}$, and held at $220^{\circ} \mathrm{C}$ for $10 \mathrm{~min}$. After deconvolution using the automated mass spectral deconvolution and identification system AMDIS version 2.71 (NIST; National Institute of Standards and Technology, USA), each volatile compound was identified by comparison of the obtained MS fragment patterns with those in the NIST library. The retention time (RT) of each compound was converted to its Kovats retention index (RI) using $\mathrm{n}$-alkanes from $\mathrm{C}_{8}$ to $\mathrm{C}_{20}$ (in n-pentane; GL Sciences Inc.) as references. The RIs were compared to the Kovats RIs reported in the literature. The peak areas of the target ions (TIs) of the identified compounds were integrated to compare the abundances of the volatile compounds, and the TI peak area was converted to $1 \mathrm{~g}$ of the dry weight determined from the moisture contents.

\section{Measurement of LOX activity}

LOX activity in wheat flour was assayed using a modification of the procedure described by Lulai et al. [22]. Wheat flour $(150 \mathrm{mg})$ was mixed with $1.5 \mathrm{ml}$ of cold $\left(4^{\circ} \mathrm{C}\right) 0.05 \mathrm{M}$ potassium phosphate buffer, 
Citation: Narisawa T, Nakajima H, Umino M, Kojima T, Asakura T, et al. (2017) Volatile Compounds from Japanese Noodles, "Udon," and their Formation During Noodle-Making. J Food Process Technol 8: 700. doi: 10.4172/2157-7110.1000700

Page 3 of 12

pH 6.0, containing $1 \mathrm{mM}$ dithiothreitol in a $2.0 \mathrm{ml}$ microtube, which was placed in a water bath $\left(4^{\circ} \mathrm{C}\right)$ for $1 \mathrm{~h}$, vortexing for $30 \mathrm{sec}$ every $15 \mathrm{~min}$. After centrifugation at $15,000 \mathrm{rpm}$ for $15 \mathrm{~min}$ at $4^{\circ} \mathrm{C}, 1.0 \mathrm{ml}$ of the resultant supernatant was poured into another microtube. These LOX extracts were prepared daily prior to measurement. To prepare a substrate solution, linoleic acid $(0.25 \mathrm{ml})$ was added dropwise to a solution of $5.0 \mathrm{ml}$ of deoxygenated $0.05 \mathrm{M}$ borate buffer, $\mathrm{pH} 9.0$, containing $0.25 \mathrm{ml}$ of Tween-20 (Kanto Chemical Co., Inc., Tokyo, Japan), with continuous vortexing. The resultant dispersion was clarified by additional deoxygenated borate buffer and then brought to $100 \mathrm{ml}$ with deoxygenated distilled water. The final concentration of this substrate solution was $8.05 \times 10^{-3} \mathrm{M}$. Next, $2.9 \mathrm{ml}$ of $0.05 \mathrm{M}$ potassium phosphate buffer, $\mathrm{pH} 6.0$, and $0.02 \mathrm{ml}$ of the LOX extract were mixed in a cuvette, and the substrate solution was added. The absorbance at $234 \mathrm{~nm}$ and $25^{\circ} \mathrm{C}$ was recorded for 3 min using an ultraviolet-visiblenear infrared (UV-VIS-NIR) spectrophotometer (UV-3600, Shimadzu Corp., Kyoto, Japan). One unit of activity is equivalent to an increase in absorbance of one per min per gram of flour at $234 \mathrm{~nm}$ and $25^{\circ} \mathrm{C}$.

\section{Statistical analysis}

PCA was applied to the TI peak area of the volatile compounds identified by GC/MS. Analysis of variance (ANOVA) was performed with the TI peak areas from the boiled noodle samples. Tukey's HSD test was applied to the enzyme activities. All calculations were performed using $\mathrm{R}$ version 3.1.3 ( $\mathrm{R}$ Core Team, Austria) and JMP 13.1.0 (SAS Institute Inc., USA).

\section{Results}

\section{Properties of the flour and noodle samples}

The properties of the wheat flours and the moisture contents of the noodle samples are shown in Table 1 . The moisture contents were used to convert the TI peak areas from the flour and noodle samples. The moisture content of the dough samples was calculated from the moisture content of the wheat flour and the amount of added water and used to convert the TI peak area from the dough samples.

The fatty acid compositions of the wheat flour samples are shown in Table 2. Oleic (C18:1) acid was more abundant in $2^{\text {nd }}$ grade flour than in $1^{\text {st }}$ grade flour, while palmitic (C16:0) acid was abundant in $1^{\text {st }}$ grade

\begin{tabular}{|c|c|c|c|c|c|c|}
\hline Sample & Grade & $\begin{array}{c}\text { Moisture } \\
\text { (\%) }\end{array}$ & $\begin{array}{l}\text { Protein } \\
(\%)^{*}\end{array}$ & Lipid (\%) & Ash $(\%)^{*}$ & \begin{tabular}{|c|} 
Noodle \\
moisture (\%)
\end{tabular} \\
\hline \multirow{2}{*}{ N61 } & $1^{\text {st }}$ & 12.8 & 7.8 & 1.8 & 0.34 & 64.5 \\
\hline & $2^{\text {nd }}$ & 12.5 & 9.2 & 2.1 & 0.50 & 63.8 \\
\hline \multirow{2}{*}{ Sato } & $1^{\text {st }}$ & 13.3 & 8.3 & 1.9 & 0.33 & 66.1 \\
\hline & $2^{\text {nd }}$ & 13.1 & 8.7 & 2.4 & 0.47 & 66.2 \\
\hline \multirow{2}{*}{ ASW } & $1^{\text {st }}$ & 13.7 & 8.5 & 1.8 & 0.36 & 65.3 \\
\hline & $2^{\text {nd }}$ & 13.7 & 8.8 & 2.0 & 0.37 & 65.2 \\
\hline Aya & $1^{\text {st }}$ & 13.2 & 7.7 & 1.9 & 0.32 & 65.3 \\
\hline \multicolumn{7}{|c|}{ Expressed on a $13.5 \%$ moisture basis } \\
\hline
\end{tabular}

Table 1: Properties of the flour and noodle samples. flour. N61 samples had higher palmitic acid contents and lower linoleic (C18:2) acid contents than the other flour samples. The contents of palmitoleic (C16:1), stearic (C18:0), and alpha-linolenic (C18:3) acids were not significant different $(\mathrm{P}<0.01)$ among the flour samples.

\section{GC/MS analysis of volatile compounds throughout the noodle-making process}

In the GC/MS analysis (Table 3), 50 compounds, including 4 hydrocarbons, 16 alcohols, 17 aldehydes, 8 ketones, 2 furans, 1 amine, and 2 acids, were identified from their mass spectra and RIs.

\section{Statistical analyses throughout the noodle-making process}

PCA was applied to the TI peak areas of the identified compounds and yielded 63 principal components (PCs). The contribution ratios from PC1, PC2, and PC3 were 39.5\%, 22.6\%, and 11.3\%, respectively, resulting in a cumulative contribution ratio of $73.4 \%$.

On the score plot in Figure 1a, the flour samples are grouped on the left side of the plot with negative PC1 values. The dough samples are distributed near the $y$-axis, while the noodle samples are grouped on the right side with positive $\mathrm{PC} 1$ values. The $\mathrm{N} 612^{\text {nd }}$ grade sample had the highest PC1 values in the dough cluster and the noodle cluster. Each step of the preparation process was distinguished based on its PC1 values, so we compared the PC2 and PC3 values against the $\mathrm{PC} 1$ values (Figure 1).

The flour samples on the score plot in Figure 1a had negative PC1 scores. Hydrocarbons such as octane (1), decane (4), dodecane (7), and tetradecane (24) and alcohols such as 3-methyl-1-butanol (14), 3-heptanol (20), 1-hexanol (26), 3-octanol (27) and 6-methyl-5-hepten-2-ol (32) are clustered on the left side of the loading plot in Figure 1b. Therefore, these compounds are significant in distinguishing the flour samples.

The dough samples on the score plot in Figure 1a had higher PC2 scores than the flour and noodle samples. The $2^{\text {nd }}$ grade N61 dough samples had the highest PC2 scores. The $1^{\text {st }}$ grade N61 dough sample and $2^{\text {nd }}$ grade Sato dough sample are grouped with slightly higher PC2 scores, while the $1^{\text {st }}$ grade Sato and Aya samples and the $1^{\text {st }}$ grade and $2^{\text {nd }}$ grade ASW samples are grouped at the bottom of the cluster. The compounds that increased in abundance during dough preparation and then decreased during boiling contributed significantly to the PC2 scores. From the loading plot in Figure 1b, pentanal (3),1-penten-3 ol (10), (E)-2-hexenal (12), 2,3-octanedione (19), (E)-2-heptenal (21), (E)-3-octen-2-one (28), 1-octen-3-ol (30), (E,E)-3,5-octadien-2-one (42), and (E,E)-2,4-nonadienal (46) are responsible for the PC2 scores.

The noodle samples had higher PC1 scores and lower PC2 scores than the dough samples. From the loading plot in Figure 1b, heptanal (8), 2-heptenone (9), (E)-2-nonenal (39), benzaldehyde (40), and (E,E)-2,6-nonadienal (43) are grouped on the right middle side and are responsible for PC1. These compounds increased during the whole

\begin{tabular}{|c|c|c|c|c|c|c|c|}
\hline Sample & Grade & C16:0 & C16:1 & C18:0 & C18:1 & C18:2 & C18:3 \\
\hline \multirow{2}{*}{ N61 } & $1^{\text {st }}$ & $31.9 \pm 1.4^{a}$ & $0.4 \pm 0.3^{a}$ & $0.8 \pm 0.0^{\mathrm{a}}$ & $7.9 \pm 0.5^{e}$ & $56.9 \pm 1.4^{c}$ & $1.9 \pm 0.2^{\mathrm{a}}$ \\
\hline & $2^{\text {nd }}$ & $27.4 \pm 0.4^{b, c}$ & $0.5 \pm 0.1^{\mathrm{a}}$ & $0.7 \pm 0.0^{\mathrm{a}}$ & $10.2 \pm 0.1^{\mathrm{a}, \mathrm{b}}$ & $58.6 \pm 0.5^{\mathrm{b}, \mathrm{c}}$ & $2.3 \pm 0.2^{\mathrm{a}}$ \\
\hline \multirow{2}{*}{ Sato } & $1^{\text {st }}$ & $26.0 \pm 1.3^{b, c}$ & $0.5 \pm 0.1^{\mathrm{a}}$ & $0.7 \pm 0.0^{\mathrm{a}}$ & $8.7 \pm 0.2^{c, d, e}$ & $61.7 \pm 1.2^{\mathrm{a}}$ & $2.1 \pm 0.2^{\mathrm{a}}$ \\
\hline & $2^{\text {nd }}$ & $24.1 \pm 0.4^{c}$ & $0.4 \pm 0.1^{a}$ & $0.6 \pm 0.0^{a}$ & $10.7 \pm 0.1^{a}$ & $61.4 \pm 0.4^{a}$ & $2.4 \pm 0.0^{a}$ \\
\hline \multirow{2}{*}{ ASW } & $1^{\text {st }}$ & $27.4 \pm 1.1^{b, c}$ & $0.2 \pm 0.1^{\mathrm{a}}$ & $0.8 \pm 0.1^{a}$ & $8.3 \pm 0.4^{\mathrm{d}, \mathrm{e}}$ & $61.3 \pm 0.2^{\mathrm{a}}$ & $2.0 \pm 0.3^{a}$ \\
\hline & $2^{\text {nd }}$ & $27.8 \pm 1.1^{b}$ & $0.2 \pm 0.2^{\mathrm{a}}$ & $0.8 \pm 0.1^{\mathrm{a}}$ & $9.0 \pm 0.2^{\mathrm{c}, \mathrm{d}}$ & $60.0 \pm 0.4^{a, b}$ & $2.1 \pm 0.3^{a}$ \\
\hline Aya & $1^{\text {st }}$ & $28.3 \pm 0.8^{b}$ & $0.1 \pm 0.0^{a}$ & $0.6 \pm 0.1^{a}$ & $9.5 \pm 0.1^{\mathrm{b}, \mathrm{c}}$ & $59.6 \pm 0.5^{a, b, c}$ & $1.6 \pm 0.3^{a}$ \\
\hline
\end{tabular}

Values followed by different letters in the same column differ significantly $(P<0.01)$

Table 2: Percentage contributions of fatty acids in wheat flour samples $(n=3)$. 
Citation: Narisawa T, Nakajima H, Umino M, Kojima T, Asakura T, et al. (2017) Volatile Compounds from Japanese Noodles, "Udon," and their Formation During Noodle-Making. J Food Process Technol 8: 700. doi: 10.4172/2157-7110.1000700

Page 4 of 12

\begin{tabular}{|c|c|c|c|c|c|c|c|c|}
\hline \multirow{2}{*}{ No. } & \multirow{2}{*}{ Compound } & \multirow{2}{*}{$\mathrm{TI}(\mathrm{m} / \mathrm{z})$} & \multirow{2}{*}{$\mathrm{RT}(\min )$} & \multirow{2}{*}{$\begin{array}{l}\text { Calculated } \\
\text { Kovats RI }\end{array}$} & \multirow{2}{*}{$\begin{array}{l}\text { Literature }{ }^{\mathrm{a}, \mathrm{b}, \mathrm{c}, \mathrm{d}} \\
\text { Kovats RI }\end{array}$} & \multicolumn{3}{|c|}{ ANOVA } \\
\hline & & & & & & Flour & Dough & Noodle \\
\hline 1 & Octane & 114 & 5.45 & 800 & 800 & $* * *$ & $* *$ & $* * *$ \\
\hline 2 & 3-Methylbutanal & 44 & 7.74 & 916 & 912 & $* * *$ & $* * *$ & $* * *$ \\
\hline 3 & Pentanal & 44 & 10.09 & 987 & 979 & $* * *$ & $* * *$ & $* * *$ \\
\hline 4 & Decane & 142 & 10.82 & 1009 & 1000 & * & NS & ND \\
\hline 5 & Hexanal & 44 & 14.48 & 1114 & 1094 & $* * *$ & $* * *$ & $* * *$ \\
\hline 6 & 2-Butylfuran & 81 & 16.07 & 1156 & 1123 & $\star \star \star *$ & $\star \star \star *$ & $* * *$ \\
\hline 7 & Dodecane & 170 & 17.71 & 1201 & 1200 & $* * *$ & NS & $* * *$ \\
\hline 8 & Heptanal & 70 & 17.97 & 1209 & 1197 & $* * *$ & $* * *$ & $* * *$ \\
\hline 9 & 2-Heptanone & 43 & 18.05 & 1211 & 1202 & $* * *$ & $\star * *$ & $* * *$ \\
\hline 10 & 1-Penten-3-ol & 57 & 18.27 & 1218 & 1204 & $\star * *$ & $\star \star \star ~$ & $\star \star \star *$ \\
\hline 11 & 2-Pentylfuran & 81 & 18.99 & 1239 & 1240 & $* * *$ & *** & *** \\
\hline 12 & (E)-2-Hexenal & 42 & 19.27 & 1248 & 1247 & ND & $* * *$ & $\star \star \star *$ \\
\hline 13 & 2-Methyl-1-butanol & 57 & 19.85 & 1265 & 1227 & *** & $* * *$ & $\star \star \star *$ \\
\hline 14 & 3-Methyl-1-butanol & 55 & 19.97 & 1269 & 1247 & $* \star *$ & 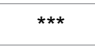 & $\star \star \star *$ \\
\hline 15 & 3-Octanone & 72 & 20.04 & 1271 & 1266 & ** & *** & *** \\
\hline 16 & Octanal & 84 & 20.95 & 1298 & 1300 & $* *$ & $* * *$ & $* * *$ \\
\hline 17 & 2-Octanone & 58 & 21.01 & 1300 & 1297 & *** & *** & $* * *$ \\
\hline 18 & 1-Pentanol & 42 & 21.10 & 1303 & 1280 & NS & $* \star *$ & $* \star *$ \\
\hline 19 & 2,3-Octanedione & 43 & 21.81 & 1328 & 1342 & ND & *** & $* \star *$ \\
\hline 20 & 3-Heptanol & 59 & 21.87 & 1330 & 1306 & NS & NS & *** \\
\hline 21 & (E)-2-Heptenal & 83 & 22.13 & 1340 & 1318 & *** & *** & *** \\
\hline 22 & 6-Methyl-5-hepten-2-one & 69 & 22.43 & 1350 & 1342 & * & ** & *** \\
\hline 23 & (E)-2-Penten-1-ol & 57 & 22.67 & 1359 & 1321 & ND & *** & *** \\
\hline 24 & Tetradecane & 85 & 22.88 & 1366 & 1400 & *** & * & ** \\
\hline 25 & Nonanal & 98 & 23.49 & 1388 & 1400 & *** & *** & $* \star *$ \\
\hline 26 & 1-Hexanol & 55 & 23.53 & 1389 & 1359 & $* *$ & *** & $* * \star$ \\
\hline 27 & 3-Octanol & 59 & 24.19 & 1414 & 1401 & *** & *** & $* \star *$ \\
\hline 28 & (E)-3-Octen-2-one & 55 & 24.37 & 1422 & 1388 & *** & $* * *$ & $* * *$ \\
\hline 29 & (E)-2-Octenal & 70 & 24.75 & 1437 & 1408 & *** & *** & *** \\
\hline 30 & 1-Octen-3-ol & 57 & 25.42 & 1463 & 1456 & *** & *** & $* * *$ \\
\hline 31 & 1-Heptanol & 70 & 25.70 & 1474 & 1467 & *** & *** & $* \star *$ \\
\hline 32 & 6-Methyl-5-hepten-2-ol & 95 & 25.84 & 1480 & 1488 & *** & *** & $* * *$ \\
\hline 33 & Acetic acid & 60 & 25.93 & 1484 & 1477 & *** & NS & * \\
\hline 34 & Decanal & 70 & 26.08 & 1490 & 1502 & *** & *** & $* * *$ \\
\hline 35 & 2-Ethyl-1-hexanol & 57 & 26.36 & 1501 & 1515 & ** & *** & *** \\
\hline 36 & (E,E)-2,4-Heptadienal & 81 & 26.45 & 1505 & 1497 & 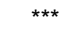 & *** & $* * *$ \\
\hline 37 & Pyrrole & 67 & 26.98 & 1528 & 1526 & NS & *** & *** \\
\hline 38 & (E,Z)-3,5-Octadien-2-one & 95 & 27.01 & 1530 & 1529 & $* * *$ & $* * *$ & $* *$ \\
\hline 39 & (E)-2-Nonenal & 70 & 27.13 & 1529 & 1527 & $* \star *$ & $* \star \star$ & *** \\
\hline 40 & Benzaldehyde & 77 & 27.17 & 1531 & 1529 & *** & *** & $* * \star$ \\
\hline 41 & 1-Octanol & 56 & 27.84 & 1562 & 1565 & *** & $\star \star \star *$ & *** \\
\hline 42 & (E,E)-3,5-Octadien-2-one & 95 & 28.20 & 1579 & 1569 & $* *$ & $* * *$ & $* * *$ \\
\hline 43 & $(\mathrm{E}, \mathrm{E})-2,6$-Nonadienal & 70 & 28.26 & 1582 & 1575 & *** & *** & *** \\
\hline 44 & (E)-2-Octen-1-ol & 71 & 29.06 & 1620 & 1618 & $\star * \star *$ & $* *$ & $* *$ \\
\hline 45 & 1-Nonanol & 55 & 29.90 & 1660 & 1666 & *** & $\star \star \star *$ & *** \\
\hline 46 & $(E, E)-2,4-N o n a d i e n a l$ & 81 & 30.81 & 1703 & 1708 & $\star * \star *$ & *** & $* * *$ \\
\hline 47 & (E,Z)-2,4-Decadienal & 81 & 32.01 & 1765 & 1758 & ND & *** & *** \\
\hline 48 & $(\mathrm{E}, \mathrm{E})-2,4$-Decadienal & 81 & 33.01 & 1816 & 1819 & ND & $* * *$ & $* * *$ \\
\hline 49 & Hexanoic acid & 60 & 33.78 & 1856 & 1849 & *** & NS & ** \\
\hline 50 & Benzyl alcohol & 108 & 34.27 & 1881 & 1886 & * & NS & ** \\
\hline
\end{tabular}

Table 3: Volatile compounds identified by GC/MS and corresponding ANOVA results. 
Citation: Narisawa T, Nakajima H, Umino M, Kojima T, Asakura T, et al. (2017) Volatile Compounds from Japanese Noodles, "Udon," and their Formation During Noodle-Making. J Food Process Technol 8: 700. doi: 10.4172/2157-7110.1000700

process and contributed significantly to differentiating $2^{\text {nd }}$ grade N61. According to the PC2 loading plot, octanal (16), nonanal (25), decanal (34), and 2-ethyl-1-hexanol (35) are responsible for the negative PC2 scores.

The ASW and Aya samples are grouped on the bottom of all clusters in Figure 2a. From the loading plot in Figure 2b, almost all compounds had positive PC3 loadings. According to the negative PC3 scores of ASW and Aya, these flour samples had different volatile compound profiles compared to the other samples (Figure 2).

\section{Statistical analyses of the noodle samples}

Of the 50 compounds identified in the noodle samples, forty-three compounds were extracted by ANOVA at $\mathrm{P}<0.001$ (Table 3). PCA was applied to the TI peak areas of these compounds, and the PCA scores and loadings in the noodle samples are plotted in Figure 3.

The PCA results are sufficiently summarized by PC1 and PC2 (Figure 3). The $2^{\text {nd }}$ grade N61 and Sato samples are distributed on the right of the score plot in Figure $3 \mathrm{a}$, and the $1^{\text {st }}$ grade and $2^{\text {nd }}$ grade ASW samples on the left. PC1 was mainly affected by the ash content, and its contribution ratio was $49.3 \%$. The $1^{\text {st }}$ grade and $2^{\text {nd }}$ grade ASW samples had similar ash contents (Table 1). Therefore, these samples had almost the same PC1 scores. PC2, with a contribution ratio of $18.5 \%$, was
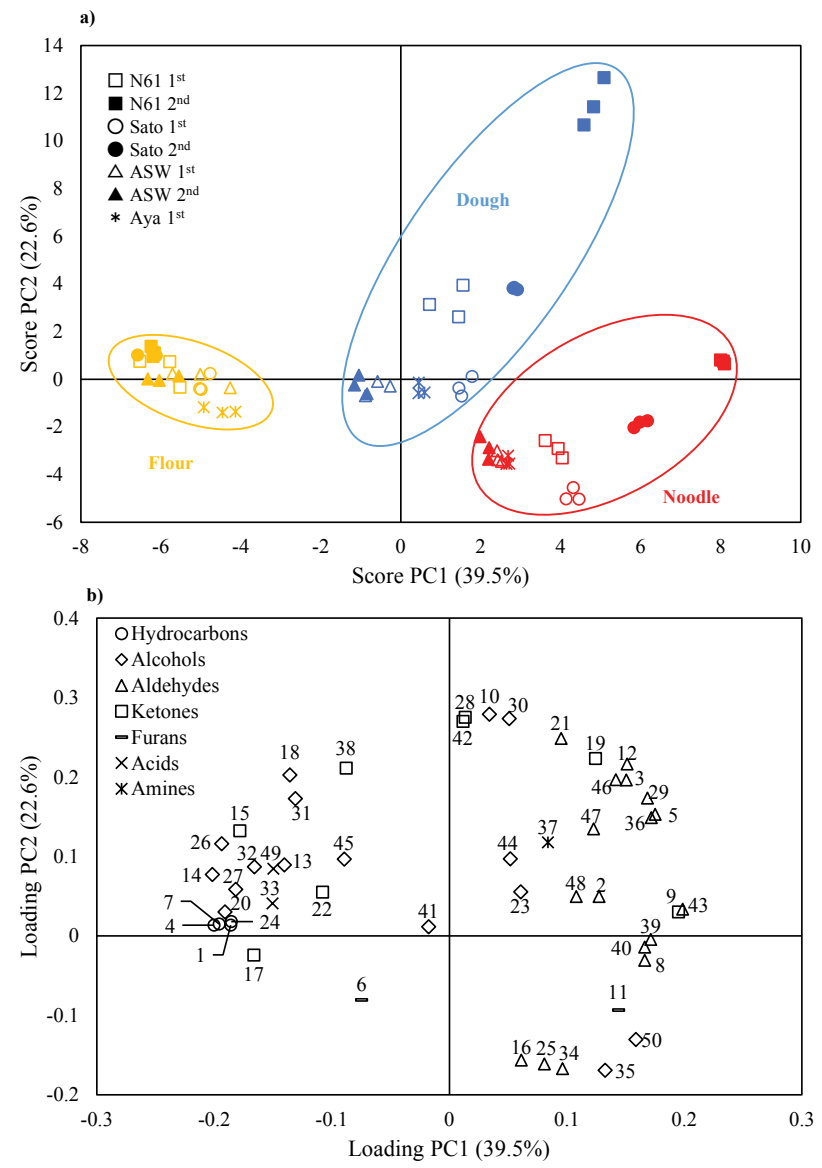

(a) Score plot of the samples. (b) Loading plot of the volatile compounds. Three analytical replicates are presented for each sample. The numbers indicate each compound shown in Table 3. The contribution ratios of the components are shown in parentheses on the corresponding axis.

Figure 1: PCA plots of PC1 and PC2 for the whole noodle-making process.


(a) Score plot of the samples. (b) Loading plot of the volatile compounds. Three analytical replicates are presented for each sample. The numbers indicate each compound shown in Table 3. The contribution ratios of the components are shown in parentheses on the corresponding axis.

Figure 2: PCA plots of PC1 and PC3 for the whole noodle-making process.

affected by the differences between the Sato and ASW samples. The $2^{\text {nd }}$ grade ASW samples and $1^{\text {st }}$ grade Aya samples had negative PC2 scores, whereas the $1^{\text {st }}$ grade N61 samples and $1^{\text {st }}$ grade Sato samples had positive PC2 values. The $1^{\text {st }}$ grade ASW, $2^{\text {nd }}$ grade Sato and N61 samples had PC2 scores of approximately 0 (Figure $3 \mathrm{a}$ ).

PC1 mainly comprised aldehydes and ketones such as 3-methylbutanal (2), pentanal (3), hexanal (5), (E)-2-hexenal (12), 3,5-octanedione (19), (E)-2-octenal (29), and (E,E)-2,4-heptadienal (36), which had positive PC1 loadings (Figure $3 \mathrm{~b}$ ).

For PC2, dodecane (7), octanal (16), 2-octanone (17), 3-heptanol (20), nonanal (25), 3-octanol (27), decanal (34), 2-ethyl-1-hexanol (35), and 1-octanol (41) made significant positive contributions, whereas 1-heptanol (31), 6-methyl-5-hepten-2-ol (32), and 1-nonanol (45) had relatively large negative loadings (Figure $3 \mathrm{~b}$ ).

\section{LOX activities}

The LOX activities of the wheat flour samples are shown in Figure 4. Only the $2^{\text {nd }}$ grade $\mathrm{N} 61$ sample had a significantly high activity $(\mathrm{P}<0.01)$.

\section{Discussion}

Changes in volatile compounds throughout the noodlemaking process

The PCA results for the whole noodle-making process indicated 
Citation: Narisawa T, Nakajima H, Umino M, Kojima T, Asakura T, et al. (2017) Volatile Compounds from Japanese Noodles, "Udon," and their Formation During Noodle-Making. J Food Process Technol 8: 700. doi: 10.4172/2157-7110.1000700

Page 6 of 12
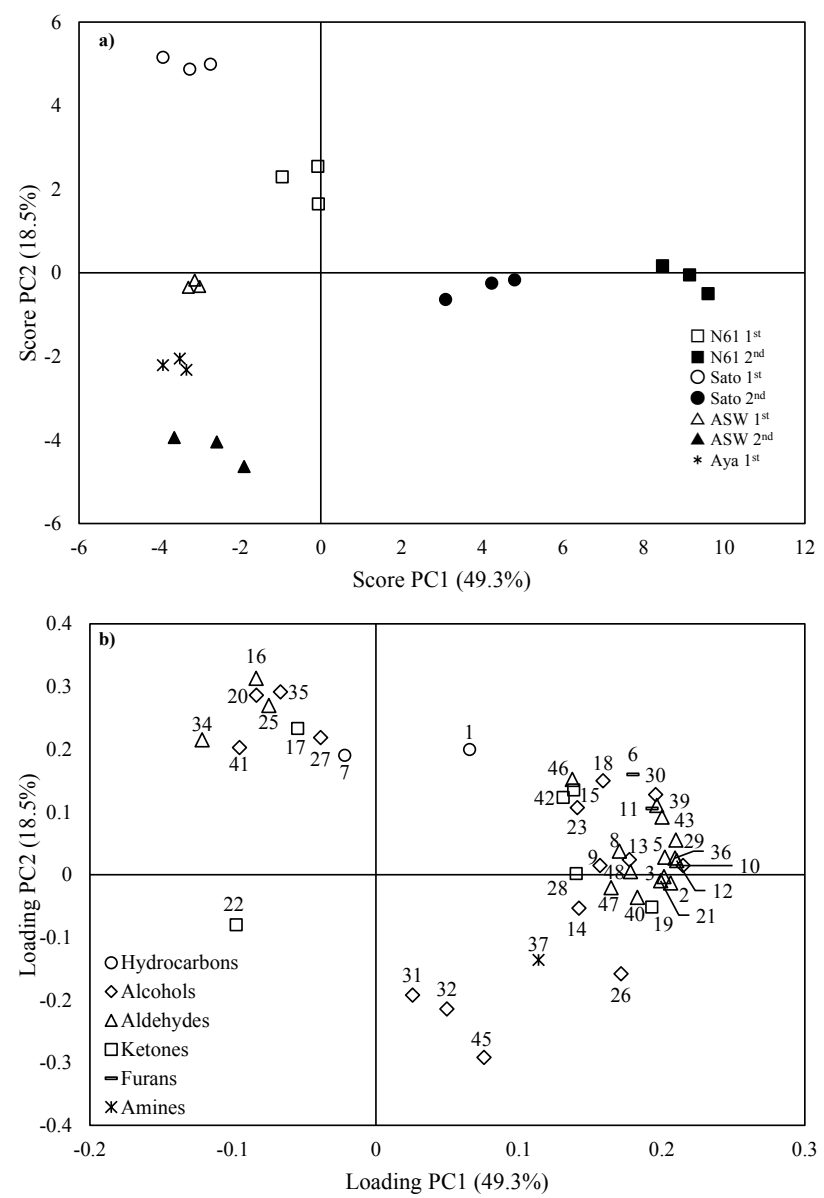

(a) Score plot of the samples. (b) Loading plot of the volatile compounds. Three analytical replicates are presented for each sample. The numbers indicate each compound shown in Table 3. The contribution ratios of the components are shown in parentheses on the corresponding axis.

Figure 3: PCA plots of PC1 and PC2 for the boiled noodle samples.



Error bars represent the standard deviation; $n=3$. Different letters above the bars denote significant differences $(P<0.01) .1^{\text {st }}$ and $2^{\text {nd }}$ represent the flour grade. ASW, Australian standard white; N61, Nourin 61; Sato, Satonosora; Aya, Ayahikari.

Figure 4: LOX activities of wheat flour samples

that the greatest changes in the volatile compound profiles occurred after the addition of water (Figure 1). Beleggia et al. [8] reported an increase in the aldehyde content and the appearance of ketones in pasta after cooking. The changes in aldehyde and ketone contents in the present study agreed with these observations. Beleggia et al. [8] also suggested that the changes in aldehyde and ketone contents during pasta cooking were caused by the thermal oxidation of lipids, rather than enzymatic oxidation. However, they have not analyzed volatile compounds at the dough step. Thus, there is no information whether an enzymatic reaction has occurred before boiling step. In the present study, significantly higher levels of aldehydes and ketones were observed in dough, before boiling, than in the other preparation stages. Therefore, the formation of these volatile compounds was possibly caused by enzymatic oxidation after the addition of water to the flour. In particular, straight-chain aldehydes and ketones made up the majority of the volatile compounds detected and were presumably products of unsaturated fatty acid decomposition. Hatanaka et al. [16,17] and Matsui et al. [18] reported that linoleic acid (C18:2) and alfa-linolenic acid (C18:3) are converted to hydroperoxy fatty acids in an oxidation reaction catalyzed by LOX. Compounds with a scent resembling freshly cut grass or plant leaves, such as hexanal and (E)-2-hexenal, are generated via a cleavage reaction by hydroperoxide lyase (HPOlyase), and these compounds were also observed in the present study (Table 2). Other straight-chain aldehydes and ketones are presumed products of similar enzymatic reactions.

In previous studies [23-25], the effect of LOX during pasta-making has been investigated. However, these studies were focused mainly on relations between LOX activities and color fading. The effect of the LOX activities with the volatile compound formation during


Error bars represent the standard deviation; $n=3$. The $y$-axes plot the mean peak area. $1^{\text {st }}$ and $2^{\text {nd }}$ represent the flour grade. ASW, Australian standard white; N61, Nourin 61; Sato, Satonosora; Aya, Ayahikari.

Figure 5: Peak areas of typical volatile compounds in each PC. 
noodle-making has not been investigated. In this study, the main compounds differentiating the noodle samples from the flour and dough were aldehydes and ketones formed by the enzymatic oxidation of unsaturated fatty acids, and LOX was presumed to a key enzyme in this enzymatic oxidation. Notably, the contents of aldehydes and ketones, such as heptanal (8), 2-heptanone (9), (E)-2-nonenal (39), benzaldehyde (40) and (E,E)-2,6-nonadienal (43), increased over the course of the entire preparation process, from flour to noodles, and these increases affected the volatile compound profiles of the noodle samples. Meanwhile, certain compounds, such as 2-methyl-1butanol (13) and 3-methyl-1-butanol (14), believed to be products of fermentation made no significant contributions to the scores of the noodle samples (Figure 1b).

Dough and noodles clustered separately in the PCA plots of the whole noodle-making process (Figure 1). The compounds remaining after boiling, particularly 2-pentylfuran (11), octanal (16), nonanal (25), decanal (34), 2-ethyl-1-hexanol (35), and benzyl alcohol (50), contributed significantly to the negative PC2 scores. These compounds either have relatively high boiling points or were detected at high concentrations, whereas compounds such as pentanal (3), 1-penten3-ol (10), (E)-2-hexenal (12), (E)-2-heptenal (21), (E)-3-octen-2-one (28), (E,E)-3,5-octadien-2-one (42), and (E,E)-2,4-nonadienal (46), which significantly contributed to the positive PC2 scores, either had low boiling points or were detected in at low concentrations. Therefore, noodles were differentiated from dough presumably by the loss of aldehydes and ketones during boiling due to volatilization or elution.

The changes in the representative compounds of each PC are shown in Figure 5. The content of 1-hexanol (26), which significantly contributed to the negative PC1 scores, decreased during the noodlemaking process (Figure 5a). The content of (E)-2-heptenal (21), which significantly contributed to the positive PC2 scores, increased after the addition of water and decreased during noodle boiling (Figure 5b). (E)2-Nonenal (39), which significantly contributed to the positive PC1 and PC3 scores, remained a significant contributor after boiling, particularly for the $2^{\text {nd }}$ grade flour and less in the ASW and Aya noodle samples than in the N61 and Sato noodle samples (Figure 5c). Bar graphs of the other compounds are shown in the supplemental data.

\section{Differences in the flour grade}

In the results of PCA (Figures 1-3), $2^{\text {nd }}$ grade flours except ASW were separated clearly from other samples. The grade of wheat flour is determined by the ash content. The ash content of milled flour increases from the center to the outer layers of wheat kernels [26]. First-grade flour is mainly composed of the central part of the wheat endosperm, and $2^{\text {nd }}$ grade flour includes the outer layers. Therefore, $2^{\text {nd }}$ grade flour has a higher ash content than $1^{\text {st }}$ grade flour, which was confirmed by the lipid content (Table 1). A previous study [27] identified the distribution of enzymes in wheat flour mill streams and found that oxidases, LOX, polyphenol oxidase, and peroxidase were enriched in the outer layers. Further, the oxidase activity and lipid substrate contents are thought to be higher in the outer layers [28]. In the present study, the $2^{\text {nd }}$ grade N61 sample had a higher LOX activity than the other samples (Figure 4). Burkwall et al. [29] reported the following. 1) Oleic (C18:1) and alpha-linoleic (C18:3) acids are enriched in the outer layers, and linoleic (C18:2) and palmitic (C16:0) acids are enriched in straight flour. 2) In a comparison of the fatty acid compositions of stream flours, $3^{\text {rd }}$ grade flours are similar to the bran and shorts. 3) The lipid content increases from $1^{\text {st }}$ grade flour to the bran. These findings were confirmed in the present study, except for that regarding linoleic acid
(Table 2). Therefore, the content of ketones and aldehydes was higher in the dough and noodle samples prepared from low-grade flour, which contained a larger proportion of LOX and their precursors.

\section{Differences among wheat varieties}

According to the PCA results (Figures 1 and 2), $2^{\text {nd }}$ grade N61 had the highest PC1-3 scores in the dough and noodle sample clusters. Moreover, the contents of aldehydes, such as (E)-2-nonenal (39), were high in N61 (Figure 5c). Meanwhile, PC3 showed that volatile compound formation in ASW and Aya was weak (Figures 2 and 5c). Interestingly, the $2^{\text {nd }}$ grade N61 sample had the highest LOX activity, whereas the $1^{\text {st }}$ grade and $2^{\text {nd }}$ grade N61 samples had lower contents of the unsaturated fatty acid substrates than the other samples. Throughout our tests, all samples underwent the same processing steps. Therefore, the volatile compound profile of the $2^{\text {nd }}$ grade N61 sample was presumed to result from the high activity of LOX. In addition, because the ash contents of $2^{\text {nd }}$ grade $\mathrm{N} 61$ and $2^{\text {nd }}$ grade Sato were similar (Table 1), the contamination rate of the outer layers of the wheat kernels of these samples might have been similar. Therefore, the higher LOX activity in $2^{\text {nd }}$ grade N61 might be due to genomic factors. Sato is a new cultivar and a successor of N61. The milling and crop yield of Sato is slightly higher than those of N61. New Japanese cultivars such as Sato have been selected for their improved milling and crop yield compared to those of ASW. As a result of this selection during wheat breeding, wheat such as Sato has presumably weakened LOX activity.

Based on our results, the unique volatile compound profile of udon prepared from N61 flour is possibly attributed to its high LOX activity and subsequent ability to generate aldehydes and ketones from unsaturated fatty acids. Therefore, these compounds appear to be important for the characteristics of udon prepared from flours such as N61. Additionally, since the aldehyde content increased after the addition of water, water addition is necessary for volatile compound analysis of wheat products. These results provide valuable insights and indications for the noodle industry as well as for wheat breeders in selecting wheat cultivars with unique characteristics for udon preparation.

\section{Conclusion}

Differences in the volatile compounds were assessed according to the stages of the noodle-making process, the flour grade, and the wheat varieties of the flour. Each stage of the noodle-making process had difference volatile compound profiles; $2^{\text {nd }}$ grade N61 showed the largest changes of volatile compounds in the noodle-making process. Meanwhile, ASW and Aya samples showed low volatile compound formation. Ketones and aldehydes were the major volatile components in the dough and noodle samples. The addition of water to flour contributes significantly to the volatile compound formation. This change was especially true for the $2^{\text {nd }}$ grade flour containing the outer layers of the wheat endosperm, which enriched enzymes such as LOX, as the majority of the ash component. Enzymatic oxidation of unsaturated fatty acids was likely the main producer of volatile compounds rather than fermentation. Aldehydes were significant components of the volatile compounds in the boiled noodles prepared from $2^{\text {nd }}$ grade N61 flour.

To date, little research has focused on volatile compound formation related to udon. Therefore, our results provide valuable insights and indications to the noodle industry and wheat breeders for the selection of wheat cultivars with unique characteristics for udon preparation.

\section{Acknowledgment}

This study was supported by a grant in aid for food science research from the 
Citation: Narisawa T, Nakajima H, Umino M, Kojima T, Asakura T, et al. (2017) Volatile Compounds from Japanese Noodles, "Udon," and their Formation During Noodle-Making. J Food Process Technol 8: 700. doi: 10.4172/2157-7110.1000700

Tojuro lijima Foundation for Food Science and Technology No. H27-14 and JSPS KAKENHI Grant Number JP17K12893.

\section{References}

1. Grosch W, Schieberle P (1997) Flavor of cereal products-A review. Cereal Chem J 74: 91-97.

2. Zhou M, Robards K, Glennie-Holmes M, Heilliwell S (1999) Analysis of volatile compounds and their contribution to flavor in cereals. J Agric Food Chem 47: 3941-3951.

3. Maeda T, Kikuma S, Araki T, Ikeda G, Takeya K, et al. (2009) The effects of mixing stage and fermentation time on the quantity of flavor compounds and sensory intensity of flavor in white bread. Food Sci Technol Res 15: 117-126.

4. Czerny M, Schieberle P (2002) Important aroma compounds in freshly ground whole meal and wheat flour -identification and quantitative changes during sourdough fermentation. J Agric Food Chem 50: 6835-6840.

5. Parker JK, Hassell GME, Mottram DS, Guy RCE (2000) Sensory and instrumental analyses of volatiles generated during the extrusion cooking of oat flours. J Agric Food Chem 48: 3497-3506.

6. Sjövall O, Lapveteläonen A, Johansson A, Kallio H (1997) Analysis of volatiles formed during oxidation of extruded oats. J Agric Food Chem 45: 4452-4455.

7. Bredie WLP, Mottram D, Guy RCE (2002) Effect of temperature and pH on the generation of flavor volatiles in extrusion cooking of wheat flour. J Agric Food Chem 50: 1118-1125.

8. Beleggia R, Platani C, Spano G, Monteleone M, Cattivelli L (2011) Metabolic profiling and analysis of volatile composition of durum wheat semolina and pasta. J Cereal Sci 49: 301-309.

9. Mariani MB, Giannetti V, Testani E (2014) HS-SPME/GC-MS method to characterize the flavour of italian pasta: Potential application to assess the quality of the products. Food Anal Method 7: 64-72.

10. Anese M, Nicoli MC, Massini R, Lerici CR (1999) Effects of drying processing on the Maillard reaction in pasta. Food Res Int 32: 193-199.

11. Suzuki T, Kim SJ, Mukasa Y, Morishita T, Noda T, et al. (2010) Effects of lipase, lipoxygenase, peroxidase and free fatty acids on volatile compound found in boiled buckwheat noodles. J Sci Food Agric 90: 1232-1237.

12. Keatkrai J, Jirapakkul W (2010) Volatile profile of khanom jeen, Thai fermented rice noodes, and the changes during the fermentation process. Sci Asia 36: 46-51.

13. Narisawa T, Kojima T, Yokobori M, Higuchi S, Suzuki Y, et al. (2015) Establishment of flavor evaluation technology for high value-added products and its application to quality control: For wheat flour cultivated in Saitama prefecture. Report Saitama Ind Technol Center 13: 28-32.
14. Starr G, Petersen MA, Jespersen BM, Hansen ÅS (2015) Variation of volatile compounds among wheat varieties and landraces. Food Chem 174: 527-537.

15. Starr G, Hansen ÅS, Petersen MA, Bredie WLP (2015) Aroma of wheat porridge and bread-crumb is influenced by the wheat variety. LWT- Food Sci Technol 63: 590-598.

16. Hatanaka A, Kajiwara T, Sekiya J (1976) Biosynthesis of trans-2-hexenal in chloroplasts from Thea sinensis. Phytochem 15: 1125-1126.

17. Hatanaka A, Kajiwara T, Sekiya J, Fujimura K (1979) Participation of 13-hydroperoxide in the formation of $n$-hexanal from linoleic acid in tea chloroplasts. Agric Biol Chem 43: 175-176.

18. Matsui K, Toyota H, Kajiwara T, Takuno T, Hatanaka A (1991) Fatty acid hydroperoxide cleaving enzyme, hydroperoxide lyase, from tea leaves. Phytochem 30: 2109-2113.

19. AACC (2000) Approved methods of the AACC (10th edn). American Association of Cereal Chemists, St. Paul, Minnesota, USA.

20. JOCS (2003) Standard methods for the analysis of fats, oils and related materials. Japan Oil Chemists' Society, Tokyo, Japan.

21. Thurnhofer S, Vetter W (2005) A gas chromatography/electron ionization-mass spectrometry-selected ion monitoring method for determining the fatty acid pattern in food after formation of fatty acid methyl esters. J Agric Food Chem 53: 8896-8903.

22. Lulai EC, Baker CW (1976) Physicochemical characterization of barley lipoxygenase. Cereal Chem 53: 777-786.

23. Carrera A, Echenique V, Zhang W, Helguera M, Manthey F, et al. (2007) A deletion at the Lpx-B1 locus is associated with low lipoxygenase activity and improved pasta color in durum wheat (Triticum turgidum ssp. durum). J Cereal Sci 45: 67-77.

24. Borrelli GM, Troccoli A, Fonzo ND, Fares C (1999) Durum wheat lipoxygenase activity and other quality parameters that affect pasta color. Cereal Chem 76 335-340.

25. Hessler TG, Thomson MJ, Benscher D, Nchit MM, Sorrells ME (2002) Association of a lipoxygenase locus, Lpx-B1, with variation in lipoxygenase activity in durum wheat seeds. Crop Sci 42: 1695-1700.

26. Elieser SP, Arthur NH (2011) Wheat flour milling. American Association of Cereal Chemists, St. Paul, Minnesota, USA.

27. Rani KU, Prasada Rao UJS, Leelacathi K, Haridas Rao P (2000) Distribution of enzymes in wheat flour mill streams. J Cereal Sci 34: 233-242.

28. Morrison WR (1978) Wheat lipid composition. Cereal Chem J 55: 548-558.

29. Burkwall MP Jr, Glass RL (1965) The fatty acids of wheat and its milled products. Cereal Chem J 42: 236-246. 


\section{Supporting Information:}
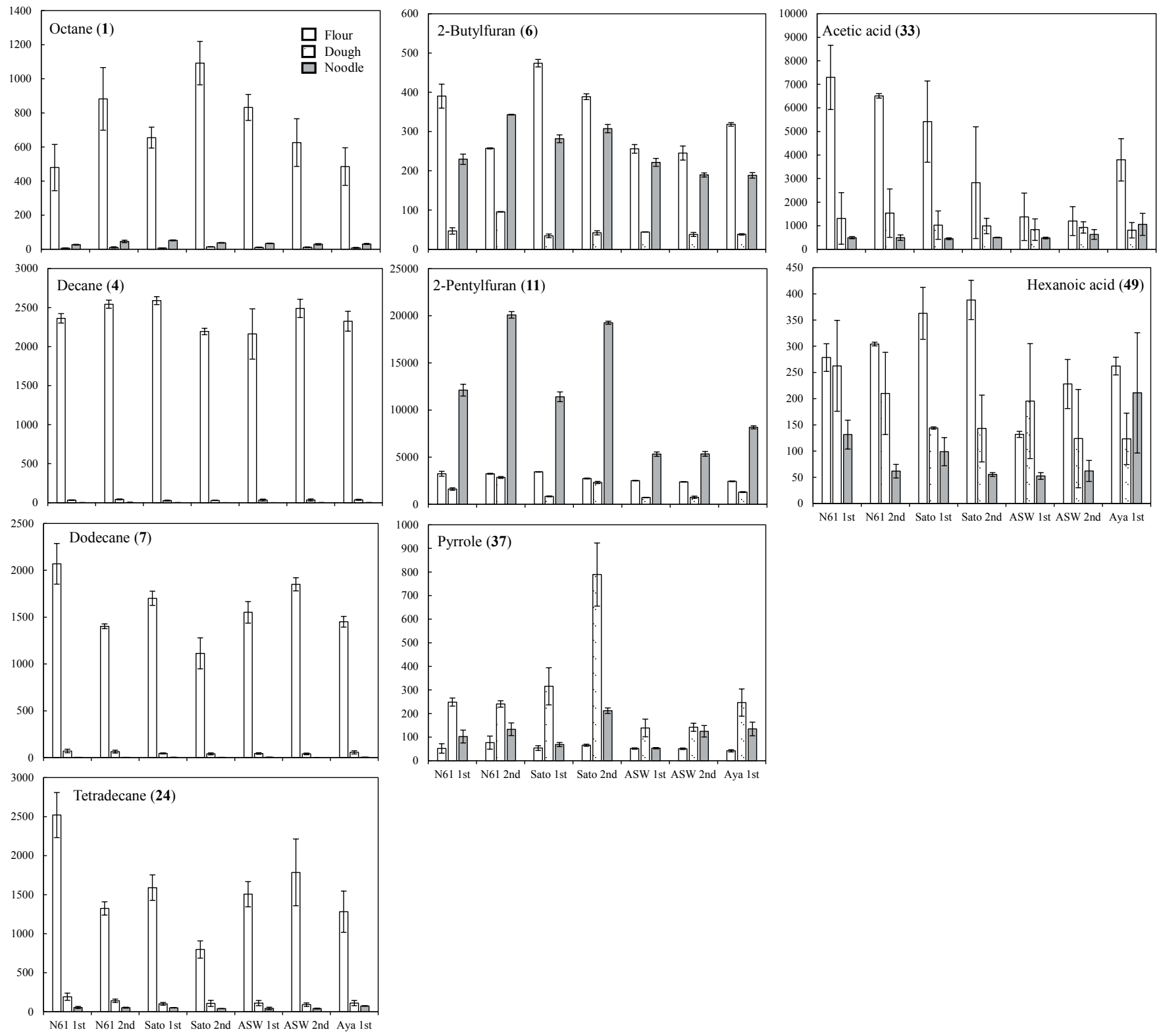

S1 Figure: Peak areas of the alkanes, furans, amine, and acids.

Error bars represent the standard deviations; $n=3$. The $y$-axes plot the mean peak area $\left(\times 10^{4}\right)$. 1 st and 2 nd represent the flour grade. ASW, Australian standard white N61, Nourin 61; Sato, Satonosora; Aya, Ayahikari. 
Citation: Narisawa T, Nakajima H, Umino M, Kojima T, Asakura T, et al. (2017) Volatile Compounds from Japanese Noodles, "Udon," and their Formation During Noodle-Making. J Food Process Technol 8: 700. doi: 10.4172/2157-7110.1000700
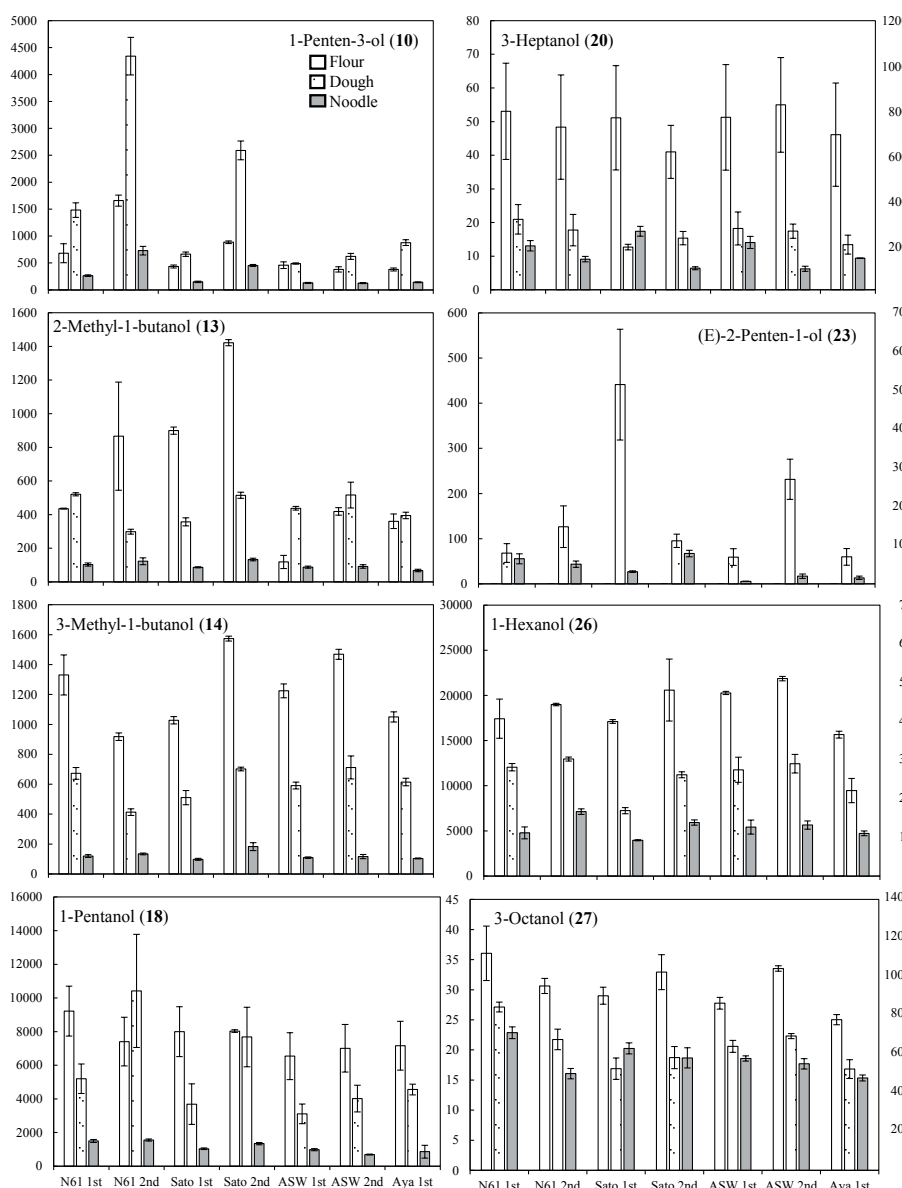

S2 Figure: Peak areas of alcohols.

Error bars represent the standard deviation; $n=3$. The $y$-axes plot the mean peak area $\left(\times 10^{4}\right)$. 1st and 2 nd represent the flour grade. ASW, Australian standard white; N61, Nourin 61; Sato, Satonosora; Aya, Ayahikari.
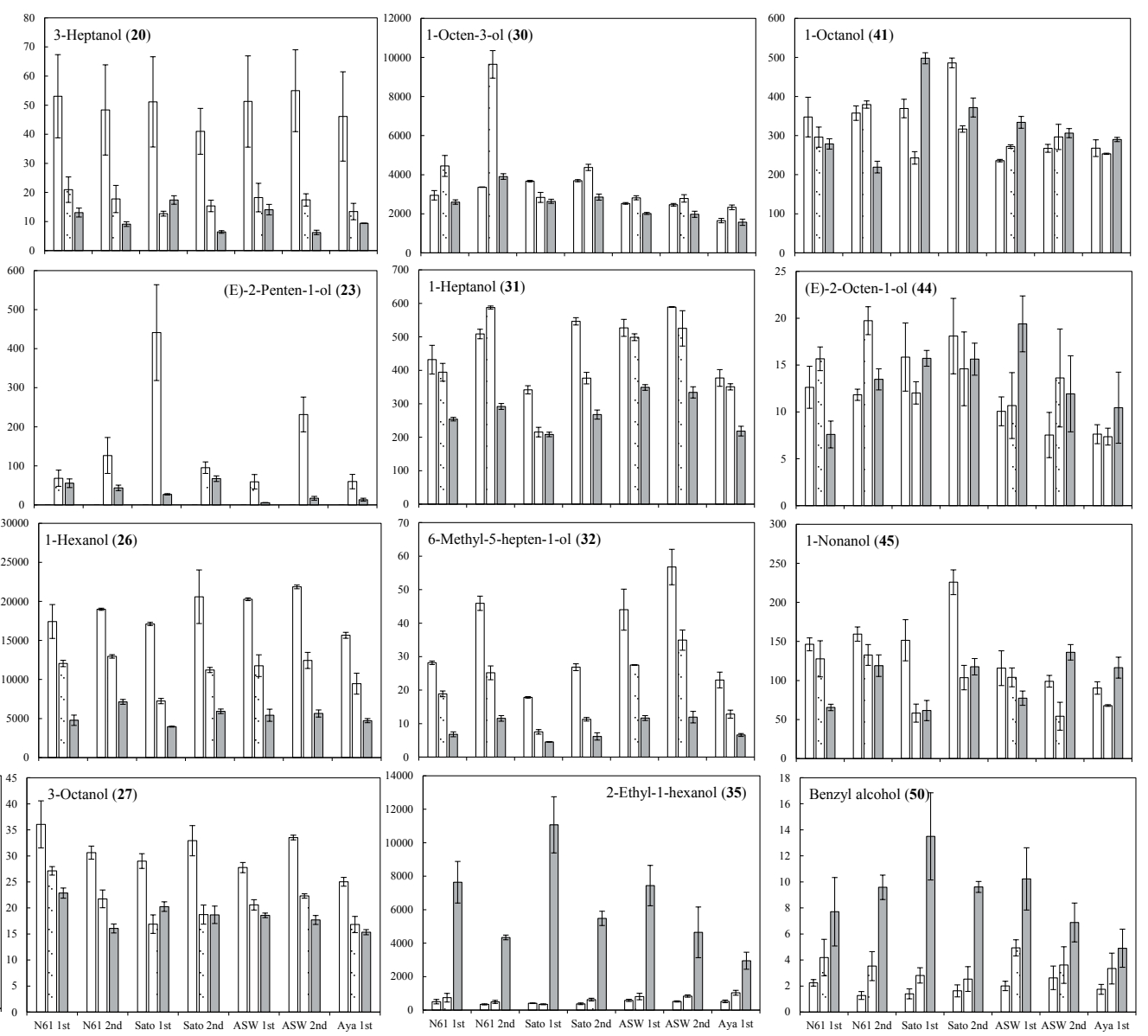
Citation: Narisawa T, Nakajima H, Umino M, Kojima T, Asakura T, et al. (2017) Volatile Compounds from Japanese Noodles, "Udon," and their Formation During Noodle-Making. J Food Process Technol 8: 700. doi: 10.4172/2157-7110.1000700
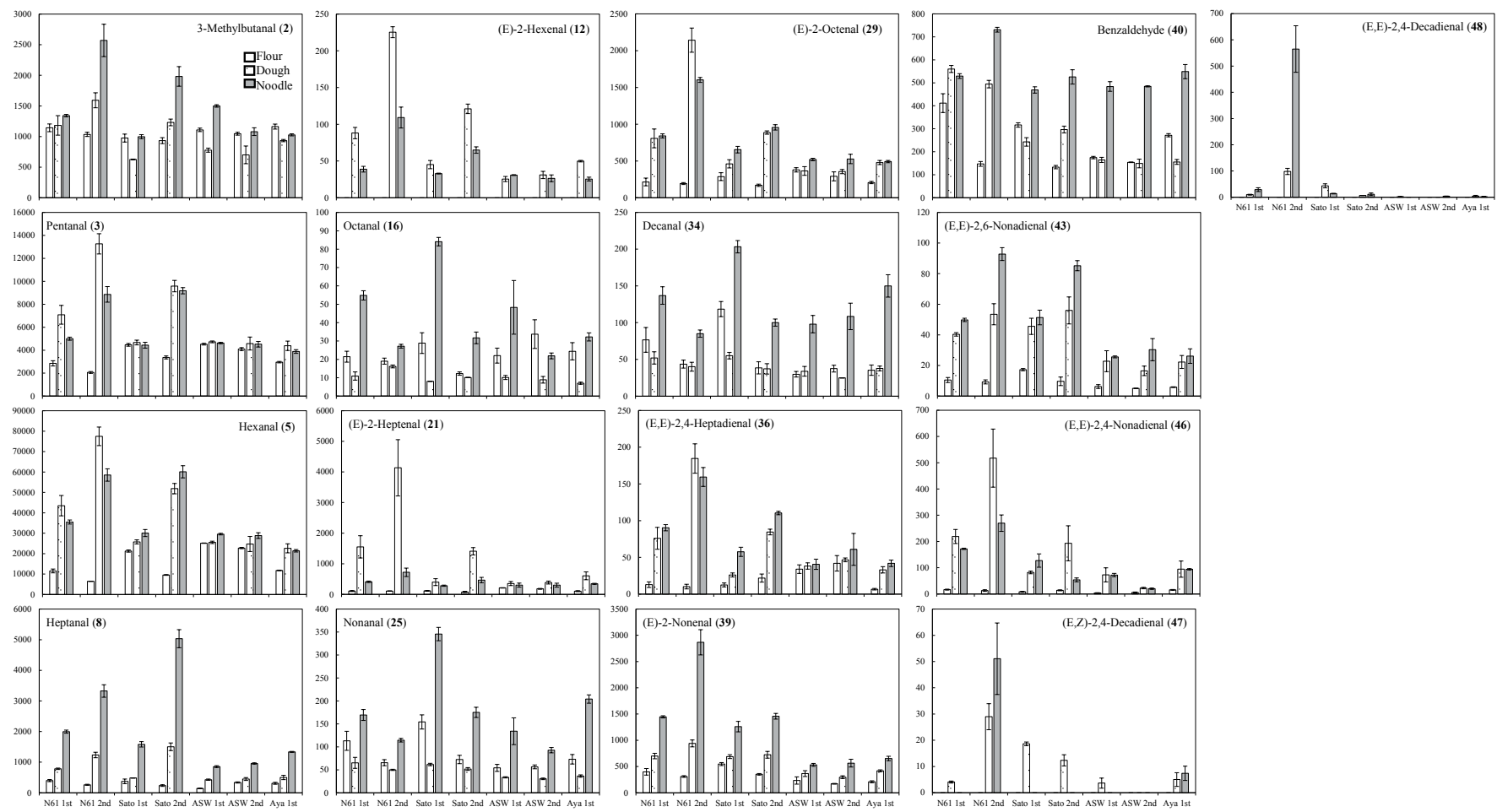

S3 Figure: Peak areas of aldehydes.

Error bars represent the standard deviation; $n=3$. The $y$-axes plot the mean peak area $\left(\times 10^{4}\right)$. 1 st and $2 n d$ represent the flour grade. ASW, Australian standard white; N61, Nourin 61; Sato, Satonosora; Aya, Ayahikari. 
Citation: Narisawa T, Nakajima H, Umino M, Kojima T, Asakura T, et al. (2017) Volatile Compounds from Japanese Noodles, "Udon," and their Formation During Noodle-Making. J Food Process Technol 8: 700. doi: 10.4172/2157-7110.1000700
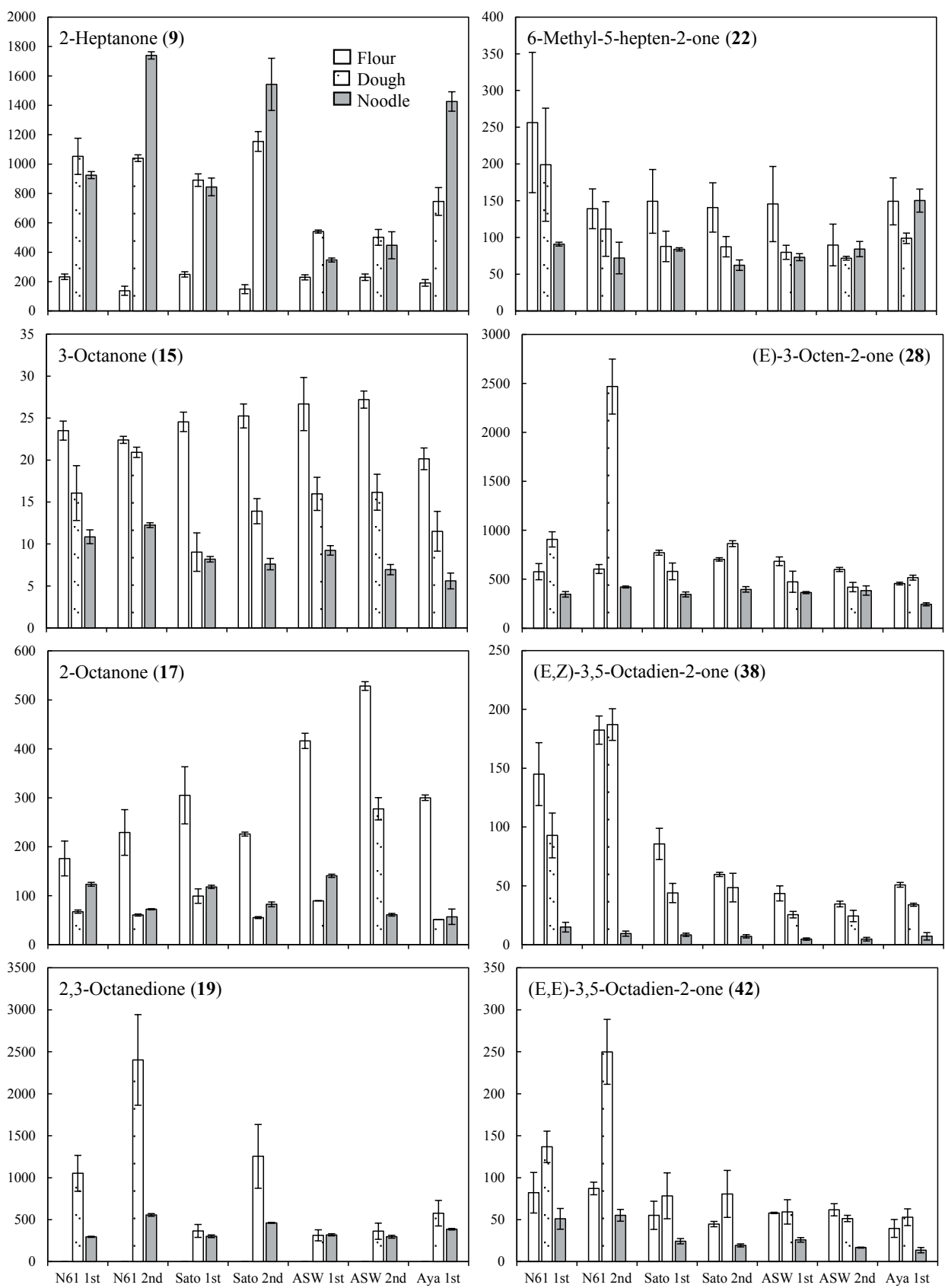

S4 Figure: Peak areas of ketones.

Error bars represent the standard deviation; $n=3$. The $y$-axes plot the mean peak area $\left(\times 10^{4}\right)$. 1st and 2 nd represent the flour grade. ASW, Australian standard white; N61, Nourin 61; Sato, Satonosora; Aya, Ayahikari. 